\title{
THE ESTIMATION OF EVANS BLUE IN PLASMA
}

\author{
BY \\ G. A. BEDWELL, J. PATTERSON, AND J. SWALE \\ From the Clinical Research Laboratories, Charing Cross Hospital, and Department of Chemical Pathology, \\ Charing Cross Hospital Medical School, London
}

(RECEIVED FOR PUBLICATION JULY 7, 1954)

\begin{abstract}
Direct colorimetric estimation of Evans blue in plasma is invalidated by the presence of opalescence or haemolysis. Various methods have been designed to overcome this difficulty and in general they have only been partially successful. The butanol method of Harington, Pochin, and Squire (1940) is time-consuming, yields variable dye recoveries, and is capable of dealing with traces of haemolysis only. The Crooke and Morris (1942) technique, involving protein precipitation with a mixture containing ethanolic phosphotungstic acid, is not readily applicable to haemolysed samples and the precipitant induces some instability in the dye. Recovery of the dye also tends to be inconsistent in the chromatographic method of Morris (1944) which uses aluminium hydroxide as absorbent. More recently a notable advance in chromatographic technique has been achieved by Allen (1951), who employs shredded tissue paper cellulose for sorption of the dye, and obtains consistent recoveries closely approximating to $97 \%$.
\end{abstract}

Trials of various forms of cellulose available to us at the time of beginning work on plasma volume estimations showed that, while some samples were capable of highly efficient separation of Evans blue from plasma, the subsequent elution invariably presented some difficulty. However, an easily prepared form of degraded amorphous cellulose was found readily amenable to both sorption and elution processes, and it was further established that the whole of the procedure was facilitated by the use of elevated temperatures. These findings became the basis of the method to be described.

\section{Method}

Reagents. -The following are required :-

Degraded Amorphous Cellulose.-A quantity, $3 \mathrm{~g}$., of acetone soluble cellulose acetate (Hercules Powder Co. Ltd.. Grade PM3E) is placed in a 500-ml. conical flask and dissolved with the aid of continuous shaking in $100 \mathrm{ml}$. of $95 \%$ acetone. While the contents of the flask are gently swirled $\mathrm{N} \mathrm{NaOH}$ is added slowly from a burette until the reaction is just alkaline. The precipitated cellulose is centrifuged at
1,200 r.p.m. for three minutes. After decanting the supernatant liquid the cellulose is washed three times with $100 \mathrm{ml}$. of physiological saline, each time lightly stirred to an even suspension with a glass rod, and then separated by centrifuging. The final suspension is made up in $250 \mathrm{ml}$. of physiological saline and stored in a refrigerator. Preparations not more than one week old should be used to ensure consistent dye recovery.

Celite (Johns-Manville, No. 545).- The absorption column is prepared from $7 \mathrm{ml}$. of cellulose suspension with about $50 \mathrm{mg}$. of celite added just before use.

Chemical Cotton (Hercules Powder Co. Ltd., Grade 13). - This most severely degraded form of cotton is used as a filter plug supporting the column.

Teepol (Shell Chemicals Ltd., Grade 530).-(a) Dilute "teepol," equal parts by volume of "teepol" and distilled water ; $(b)$ "teepol "-saline, 1 in 200 dilution of "teepol" in physiological saline.

\section{Acetone-water. $-35 \% \mathrm{v} / \mathrm{v}$.}

Evans Blue (G. T. Gurr Ltd.).-Evans blue, $100 \mathrm{mg}$.. is dissolved in $100 \mathrm{ml}$. of pyrogen-free water, autoclaved, and stored in $25-\mathrm{ml}$. sealed ampoules.

Apparatus. - The apparatus consists of a filter and a funnel heater jacket.

The Filter.-This is made by fusing two lengths of glass tubing with bores of $2 \mathrm{~cm}$. and $5 \mathrm{~mm}$. respectively. The wider tube is tapered to form the neck of the filter and junction with the narrower tube, whose lower end is cut off obliquely. The wide upper part of the filter should measure $10 \mathrm{~cm}$. in length and the lower narrow end about $4 \mathrm{~cm}$.

Funnel Heater Jacket.-A standard copper jacket is used, 6 in. internal diameter across the top.

Technique.-This is as follows :-

Injection of Dye and Blood Sampling.-Twenty millilitres of the dye solution is injected intravenously into one arm from a syringe, the delivery of which was checked by weighing. Exactly 10 minutes later a $10-\mathrm{ml}$. blood sample is taken from the oppo. site arm without venous stasis, and prevented from clotting by use of Wintrobe's anticoagulant mixture. The packed cell volume is determined by the standard Wintrobe method and the remainder of the dyed sample is centrifuged for 15 minutes. 
Determination of Evans Blue.-A plug of chemical cotton is packed into the neck of the filter sufficiently tightly to allow a flow rate of approximately $1 \mathrm{ml}$. per minute when using a $10 \mathrm{~cm}$. head of distilled water. The filter is then suspended by a clamp in the centre of the funnel heater jacket in which the water is kept very gently boiling. The position of the filter is adjusted so as to maintain its contents at approximately $45^{\circ} \mathrm{C}$. throughout the sorption and elution stages of the procedure. The suspension used to form the column and all washing and eluting fluids are first heated to $50^{\circ} \mathrm{C}$. in a water bath immeciately before their use on the column.

Celite suspended in "teepol "-saline is transferred to the filter, using a wide-bore Wright's pipette, and allowed to settle under gravity to form a layer $1.5 \mathrm{~cm}$. deep. When about $1 \mathrm{~cm}$. of fluid remains above the celite, the cellulose-celite suspension is added and washed twice with $10 \mathrm{ml}$. of "teepol "-saline. This forms an adsorbing layer about $7 \mathrm{~mm}$. deep on a lower layer of pure celite. At no time is the column allowed to be free from fluid, nor, once the column is formed, should the fluid depth above the surface ever exceed $2 \mathrm{~cm}$. Subsequent additions of fluid to the column should all be run carefully down the sides of the funnel.

To $4 \mathrm{ml}$. of dye-plasma contained in a $25-\mathrm{ml}$. beaker is added $2 \mathrm{ml}$. of dilute "teepol," mixing being effected by gentle rotation so as to avoid bubble formation. The mixture is warmed to $50^{\circ} \mathrm{C}$. for 10 minutes and transferred to the column as completely as possible with the aid of a Wright's pipette. When the plasma mixture passes through the column so that only a 3-4 mm. layer remains above the surface, $2 \mathrm{ml}$. of pre-heated "teepol "-saline is used to rinse the beaker and is then transferred to the column, the process being repeated with a further $2 \mathrm{ml}$. of "teepol "-saline, and then finally with $1 \mathrm{ml}$. of this washing liquid. Just before the last rinse recedes into the column the filter tip is rapidly washed with a jet of distilled water to remove any trace of protein, and the elution acetone is added so as to maintain a layer of about $10 \mathrm{~mm}$. above the cellulose. As the acetone penetrates, the dye moves as a sharp blue band down the column. When it enters the lower celite layer, the eluate is collected in a graduated $10-\mathrm{ml}$. cylinder until a volume of $6.5 \mathrm{ml}$. is reached. This is cooled to room temperature and made up to a volume of $7 \mathrm{ml}$. with $35 \%$ acetone. After thorough mixing the intensity of colour is read immediately in a Spekker absorptiometer against a blank of aqueous acetone, using Ilford filters 607. The total time taken, from obtaining the dyed sample of blood to the final reading, is approximately one hour.

\section{Results}

Light Absorption of Evans Blue in 35\% Acetone.-The calibration curve (Fig. 1) was made from serial dilutions, prepared by adding from an Agla micrometer syringe known amounts of
Fig. 1.-Relationship between optical density and amount of dye in $7 \mathrm{ml}$. of $35 \%$ aqueous acetone (Spekker absorptiometer: Ilford 607 filter).

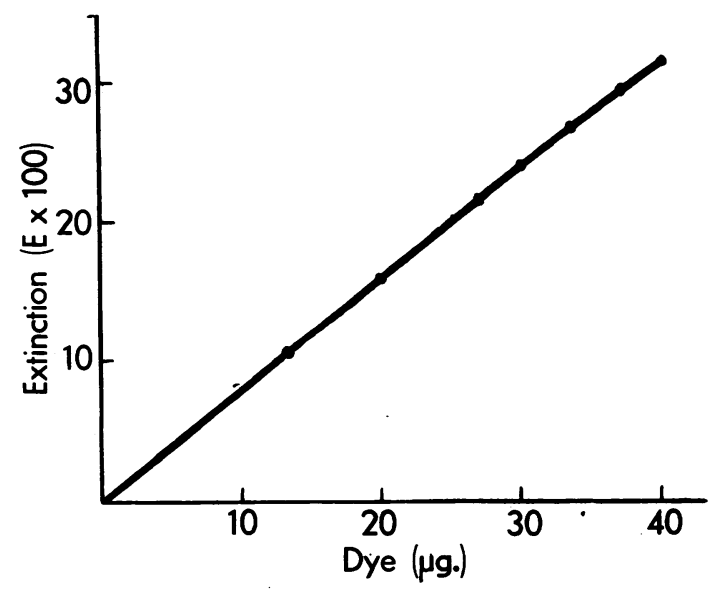

a standard solution of Evans blue, to make a total volume of $7 \mathrm{ml}$.

These results were not influenced by the incorporation of up to $2 \mathrm{ml}$. of washing liquid in the $7 \mathrm{ml}$. volume. Thus in estimations on plasma the small volume of washing liquid passing into the receiver does not affect the readings.

Recovery of Evans Blue from Non-haemolysed Plasma.-Thirty-two estimations were carried out on three different concentrations of dye in samples of fresh plasma of widely different optical character, ranging from very clear to grossly turbid. The results (Table I) show that there is no appreciable difference in the mean recoveries and standard deviations. These concentrations cover the range most commonly encountered when estimating plasma volumes in man, using $20 \mathrm{mg}$. doses of Evans blue intravenously.

TABLE I

RECOVERY OF DYE FROM NON-HAEMOLYSED PLASMA

\begin{tabular}{|c|c|c|c|c|}
\hline \multirow{2}{*}{$\begin{array}{l}\text { No. of } \\
\text { Deter- } \\
\text { minations }\end{array}$} & \multirow{2}{*}{$\begin{array}{c}\text { Evans Blue } \\
\text { Present in } 4 \mathrm{ml} . \\
\text { Plasma }(\mu \mathrm{g} .)\end{array}$} & \multicolumn{2}{|c|}{ Recovery (\%) } & \multirow{2}{*}{$\begin{array}{l}\text { Standard } \\
\text { Deviation }\end{array}$} \\
\hline & & Mean & Range & \\
\hline $\begin{array}{r}6 \\
20 \\
6\end{array}$ & $\begin{array}{l}30 \cdot 8 \\
26 \cdot 7 \\
23 \cdot 5\end{array}$ & $\begin{array}{l}97 \cdot 3 \\
97 \cdot 0 \\
97 \cdot 3\end{array}$ & $\begin{array}{l}97 \cdot 0-97.5 \\
96 \cdot 2-97.7 \\
96 \cdot 7-97 \cdot 8\end{array}$ & $\begin{array}{l}0.33 \\
0 \cdot 26 \\
0.48\end{array}$ \\
\hline
\end{tabular}

Recovery of Evans Blue from Haemolysed Plasma.-To three test-tubes each containing $4 \mathrm{ml}$. of fresh plasma were added haemolysed red cell solutions to give respectively a content of $1 \mathrm{mg}$., $2 \mathrm{mg}$., and $4 \mathrm{mg}$. of haemoglobin before the addition of Evans blue. As is shown in Table II, these quantities of haemoglobin did not alter recovery of the dye. The blood pigment was easily 
TABLE II

RECOVERY OF DYE FROM HAEMOLYSED PLASMA

\begin{tabular}{c|c|c}
\hline $\begin{array}{c}\text { Hb Present } \\
\text { (mg.) }\end{array}$ & $\begin{array}{c}\text { Evans Blue in 4 ml. } \\
\text { Plasma ( } \mu \mathrm{g} .)\end{array}$ & $\begin{array}{c}\text { Recovery } \\
(\%)\end{array}$ \\
\hline 0 & 27.7 & 97.2 \\
1.0 & 27.7 & 96.7 \\
2.0 & 27.7 & 96.7 \\
4.0 & 27.7 & 97.2 \\
\hline
\end{tabular}

visible as it passed through the column with the plasma during the adsorption and washing stages.

Results on Normal Males.-Plasma volume estimations were carried out on 10 healthy male subjects of 21 to 28 years of age. Three estimations were made on each subject at intervals of approximately one week. Conditions for each estimation were standardized by admission to hospital for one night, ensuring 10 hours' rest in bed.

Nothing was allowed by mouth after 8 p.m. apart from water and fruit drinks and the test was performed at the same hour each morning before rising. The plasma volume was determined by the present method and also by direct colorimetry as described by Mollison (1951). The latter method necessitated taking a sample of blood before the injection of the dye ; this was also required on the second and third estimations by the chromatographic method as the concentration of the residual dye* in these pre-injection samples had to be determined and taken into account in the final estimation. The results of this series of cases without obvious cloud or haemolysis is shown in Table III, those for the chromatographic method being corrected for a $3 \%$ loss in the process. The mean by the chromatographic method described was $44.9 \mathrm{ml} . / \mathrm{kg}$., and by direct colorimetry was $47.1 \mathrm{ml} . / \mathrm{kg}$.

Only one case, whose plasma was very cloudy, was examined by the direct method to see how it compared with the elution method. Two determinations were made at an interval of three weeks giving values of 65.8 and $69.1 \mathrm{ml} . / \mathrm{kg}$. as against 47.1 and $47.3 \mathrm{ml}$. $/ \mathrm{kg}$. for the elution method, thus showing a much wider discrepancy of results than any obtained on clear samples.

\section{Discussion}

The method described represents a convenient procedure for isolating the dye from plasma and measuring its concentration in simple solution in such a way as to obviate completely the vitiating effects of haemolysis and lipaemia upon the esti-

\footnotetext{
With the present technique dye has been detected in the plasma as long as 36 days after a single injection.
}

TABLE III

COMPARISON OF PRESENT ELUTION AND DIRECT METHODS OF ESTIMATING PLASMA VOLUME

\begin{tabular}{|c|c|c|c|c|}
\hline \multirow{2}{*}{ Subject } & \multirow{2}{*}{$\begin{array}{c}\text { Weight } \\
\text { (kg.) }\end{array}$} & \multicolumn{2}{|c|}{ Plasma Volume (ml./kg.) } & \multirow{2}{*}{$\begin{array}{c}\text { P.C.V. } \\
(\% \\
\text { Uncorrected) }\end{array}$} \\
\hline & & Eluted & Direct & \\
\hline 1 & $66 \cdot 4$ & $\begin{array}{l}60 \cdot 5 \\
56 \cdot 6 \\
57.9\end{array}$ & $\begin{array}{l}58 \cdot 0 \\
57 \cdot 6 \\
62 \cdot 4\end{array}$ & $\begin{array}{l}45 \\
45 \\
45\end{array}$ \\
\hline 2 & $66 \cdot 8$ & $\begin{array}{l}43.9 \\
41.0 \\
41.9\end{array}$ & $\begin{array}{l}40 \cdot 9 \\
44 \cdot 3 \\
46 \cdot 4\end{array}$ & $\begin{array}{l}47 \\
47 \\
47\end{array}$ \\
\hline 3 & 73.6 & $\begin{array}{l}50 \cdot 2 \\
46 \cdot 9 \\
50 \cdot 5\end{array}$ & $\begin{array}{l}53 \cdot 1 \\
48 \cdot 9 \\
52 \cdot 1\end{array}$ & $\begin{array}{l}46 \\
46 \\
45\end{array}$ \\
\hline 4 & $64 \cdot 1$ & $\begin{array}{l}42.9 \\
42.7 \\
43.9\end{array}$ & $\begin{array}{l}44 \cdot 6 \\
43 \cdot 7 \\
47 \cdot 5\end{array}$ & $\begin{array}{l}47 \\
47 \\
47\end{array}$ \\
\hline 5 & $63 \cdot 2$ & $\begin{array}{l}43.6 \\
48.9 \\
48.0\end{array}$ & $\begin{array}{l}45 \cdot 7 \\
52 \cdot 1 \\
53 \cdot 8\end{array}$ & $\begin{array}{l}48 \\
46 \\
48\end{array}$ \\
\hline 6 & $69 \cdot 1$ & $\begin{array}{l}42 \cdot 7 \\
41 \cdot 1 \\
45 \cdot 2\end{array}$ & $\begin{array}{l}45 \cdot 9 \\
47 \cdot 4 \\
46 \cdot 2\end{array}$ & $\begin{array}{l}46 \\
47 \\
45\end{array}$ \\
\hline 7 & $67 \cdot 3$ & $\begin{array}{l}47.9 \\
51.0 \\
52.8\end{array}$ & $\begin{array}{l}49 \cdot 4 \\
46 \cdot 4 \\
53 \cdot 3\end{array}$ & $\begin{array}{l}43 \\
44 \\
42\end{array}$ \\
\hline 8 & $68 \cdot 2$ & $\begin{array}{l}38.8 \\
36 \cdot 4 \\
39.0\end{array}$ & $\begin{array}{l}41 \cdot 9 \\
40 \cdot 3 \\
40 \cdot 7\end{array}$ & $\begin{array}{l}50 \\
51 \\
50\end{array}$ \\
\hline 9 & $60 \cdot 9$ & $\begin{array}{l}39 \cdot 0 \\
36 \cdot 5 \\
37.6\end{array}$. & $\begin{array}{l}40 \cdot 0 \\
39 \cdot 6 \\
37 \cdot 7\end{array}$ & $\begin{array}{l}54 \\
52 \\
53\end{array}$ \\
\hline \multirow[t]{2}{*}{10} & $76 \cdot 4$ & $\begin{array}{l}36 \cdot 9 \\
40 \cdot 6 \\
42 \cdot 2\end{array}$ & $\begin{array}{l}40 \cdot 7 \\
43 \cdot 5 \\
48 \cdot 0\end{array}$ & $\begin{array}{l}47 \\
48 \\
47\end{array}$ \\
\hline & & $\begin{array}{c}\text { Mean } \\
44.9\end{array}$ & $\begin{array}{c}\text { Mean } \\
47 \cdot 1\end{array}$ & $\begin{array}{c}\text { Mean } \\
47 \cdot 2\end{array}$ \\
\hline
\end{tabular}

mations. It compares favourably with that of Allen to which reference has already been made. Our experience with various preparations of shredded tissue paper, and also of cellulose powder specially prepared for chromatography, has shown the degraded form of amorphous cellulose regenerated from cellulose acetate to be more suitable both in respect of absorption of dye and its subsequent elution. Whereas $130 \mathrm{mg}$. of tissue paper cellulose is required in the Allen technique, about $50 \mathrm{mg}$. of amorphous cellulose suffices for the present type of absorption column. The less cellulose required to constitute the column the greater the ease of complete elution. Slight losses have been encountered in washing the column with saline alone. These were avoided by the "teepol"saline washing used in the present method, but even in these conditions it is essential to keep the total amount of washings to a minimum. At ordinary room temperatures the elution process has occasionally left a visible trace of blue on the surface of the column. The heating of the atmosphere surrounding the column has completely eliminated this factor as a source of slightly 
inconsistent results. The alternative form of heating by surrounding the column with warm water has been found to have the disadvantage in the elution process of tending to create some channelling in the area of contact with the glass funnel. Most of the preliminary work was done in sintered glass filter tubes. Under these circumstances a few tiny particles of celite and cellulose were carried through with the eluate, a result attributable to the use of the detergent. The substitution for a sintered glass disc of a cotton plug made of severely degraded material provided clearer eluates for a given filtration rate. To obtain complete clarity with the use of sintered glass funnels the disc had to be of such fine porosity as to slow down the whole process to an inconvenient degree. Further, prolonged contact of the dye with the constituents of the column generally led to slight loss in the recovery of dye so that it was essential to resort to a process in which the elution rate was fairly rapid.

Because coloured impurities in Evans blue introduce an error into plasma volume determinations (Leeson and Reeve, 1949), a careful preliminary search was instituted for a preparation which contained only traces of the red impurity, a common contaminant of commercial products. The results recorded here are those which have been obtained by using a dye containing little more than a trace of this red component. It was of such small concentration that its presence did not affect the maximum absorption of light by more than $0.5 \%$.

The efficiency of the combined sorption and elution process may be gauged by the fact that it was found possible to detect concentrations of dye as low as $10 \mu \mathrm{g}$. per $100 \mathrm{ml}$. plasma as an easily visible faint blue on the surface of the column, and that at the end of every elution process the column when compared with a freshly prepared unused column showed no detectable difference in colour.

The results of the estimations performed on normal male subjects show that the mean of the chromatographic method was $2.2 \mathrm{ml}$. $/ \mathrm{kg}$. less than the mean obtained by direct colorimetry. Moreover the range of values on each individual subject was generally appreciably less by the present method than by the direct method. The discrepancies between the two sets of results may be partly explained by the fact that a single standard calibration curve was used for all the direct determinations, being prepared from known quantities of dye added to pooled fresh clear plasma. Had a standard been prepared in the corresponding preinjection sample at each estimation the results might have been closer, but this would have involved taking unduly large blood samples.

Our mean value of $44.9 \mathrm{ml} . / \mathrm{kg}$. by the chromatographic method is in close agreement with the mean value of 44.7 and 45 for normal males reported by Noble and Gregersen (1946) and Henschel, Mickelsen, Taylor, and Keys (1947) respectively. The mean haematocrit values of these workers were also nearly identical with our own.

\section{Summary}

A chromatographic method is described for estimating Evans blue in plasma using a column of degraded amorphous cellulose. The dye separates as a narrow band on the surface of the column and is subsequently eluted with aqueous acetone. Consistent recoveries of $97 \%$ are obtained and the analyses are not affected by the presence of opalescence or haemolysis. Comparative results of estimating plasma volume by this elution method and the direct method on normal male subjects are recorded.

We have to express our warmest thanks to Messrs. Hercules Powder Co. Ltd. for placing at our disposal specimens of high-grade cellulose acetate and chemical cotton, and to Messrs. Shell Chemicals Ltd. for a range of samples of anionic detergents.

\section{REFERENCES}

Allen, T. H. (1951). Proc. Soc. exp. Biol. N.Y., 76, 145. Crooke, A. C., and Morris, C. J. O. (1942). J.'Physiol., Lond., 101, 217.

Harington, C. R., Pochin, E. E., and Squire, J. R. (1940). Clin. Sci., 4,311 .

Henschel, A., Mickelsen, O., Taylor, H. L., and Keys, A. (1947) Amer. J.' Physiol., 150, 170.

Leeson, D., and Reeve, E. B. (1949). J. Physiol., Lond., 109, 170.

Mollison, P. L. (1951). Blood Transfusion in Clinical Medicine. Blackwell Scientific Publications, Oxford.

Morris, C. J. O. (1944). Biochem. J., 38, 203.

Noble, R. P., and Gregersen, M. I. (1946). J. clin. Invest., 25, 172. 